\title{
O conceito da cadeira no design-arte: Materialização da personalidade e a experiência do usuário com o objeto.
}

\author{
The chair's concept in the Art-design: The materialization of Personality and \\ Experience of the user and the Object.
}

FERNANDES, Adriana Sousa; Mestre em Artes Visuais; Escola de Belas Artes - UFBA

drinandes@hotmail.com

MARIÑO, Suzi Maria; Pós Dr.ạ; Escola de Belas Artes - UFBA

suzimarino@gmail.com

GORDILHO, Maria Virginia; Dr.a; Escola de Belas Artes - UFBA

vigagordilhoufba@gmail.com

\section{Resumo}

Em uma cadeira se constrói um conjunto de qualidades inseridas em sua forma, destas podem materializar personalidades e experiências que marcam o usuário. Neste estudo, pretendemos trazer aspectos e momentos que caracterizam sua forma como ferramenta de transposição da relação entre corpo e objeto. Como a forma identifica uma personalidade ou marca uma relação com o usuário? Para responder tal questionamento, foram traçadas relações com a cadeira de Van Gogh, como também a cadeira Mole do designer Sérgio Rodrigues, identificando conceitos de diversos autores. Os resultados encontrados indicam o entrelace entre o objeto e o ser humano, concluindo assim que para conseguir compreender os artefatos, faz-se necessário ter a consciência de que eles podem mudar, a depender do momento e dos fatores que o estabelecem, sendo o tempo o fator que engloba todas as categorias e influencia em seu significado.

Palavras Chave: design; cadeira; experiência do usuário e materialização da personalidade.

\begin{abstract}
A chair is built by a set of qualities inserted in its form, they can materialize personalities and experiences that mark the user. The aim of this study is bringing aspects and moments that characterize its form as a tool for transposing the relation between body and object. How does the form identify a personality or brand a relationship with the user? To answer such question, relationships were drawn by the Van Gogh chair, as well as the Mole chair by the designer Sérgio Rodrigues, identifying concepts of many authors. The results indicate the interplay between the object and the human being, thus concluding that in order to understand the artifacts, it is necessary to be aware that they can change, depending on the moment and the factors that establish it, being the time the factor thatcontain all categories and influences their meaning.
\end{abstract}

Keywords: design; chair, user experience and personality materialization. 


\section{Introdução}

Pode-se observar que, ao longo dos tempos, a cadeira se tornou um ícone para várias gerações, carregando um valor de cultura material facilmente percebido na sua constante presença em estudos antropológicos, sociais e ergonômicos.

Em paralelo a isso, ela começou a carregar também outras relações que não se restringiam à sua função originária, a do sentar, como também foi capaz de transportar características que poderiam descrever personalidades, ou até mesmo servir para contemplação ou decoração de um ambiente, como uma escultura, sugerindo significados e relações de acordo às suas características visuais e morfológicas.

Como exemplo disso, temos a W.W Stool, (Figura 1), a banqueta de 1990, criada pelo designer Philippe Stark e produzida pela Vitra, empresa Suíça de mobiliário, que é categorizada como "objeto escultural". Sugere-se também a probabilidade de ser usada como banqueta, verificando-se assim, a relação entre forma e significado, destacando-se que a "função de tal objeto é a possibilidade de não ser usado" (JEUDY, 1999 apud CARDOSO, 2016, p. 123). Ou seja, aqui o objeto assume uma função de contemplação escultural, além de continuar servindo para a função do sentar, cabendo, também, na categoria de obra de arte, subvertendo-se a ideia preconcebida sobre sua forma. Entra-se em um amplo campo de discussão sobre a função dos objetos, que a qualquer momento pode ser mudada pelo usuário, capaz de identificá-los através de outro ponto de vista diferente daquele de sua origem, criação e fabricação. Cardoso (2016) reforça: "Ao pensar a ação do sentar como experiência e não como artefato específico, o projetista se liberta de estruturas preexistentes e ganha a possibilidade de criar soluções realmente inovadoras." (CARDOSO, 2016, p. 124).

Figura 1 - W.W. Stool 1990, designer Philippe Stark
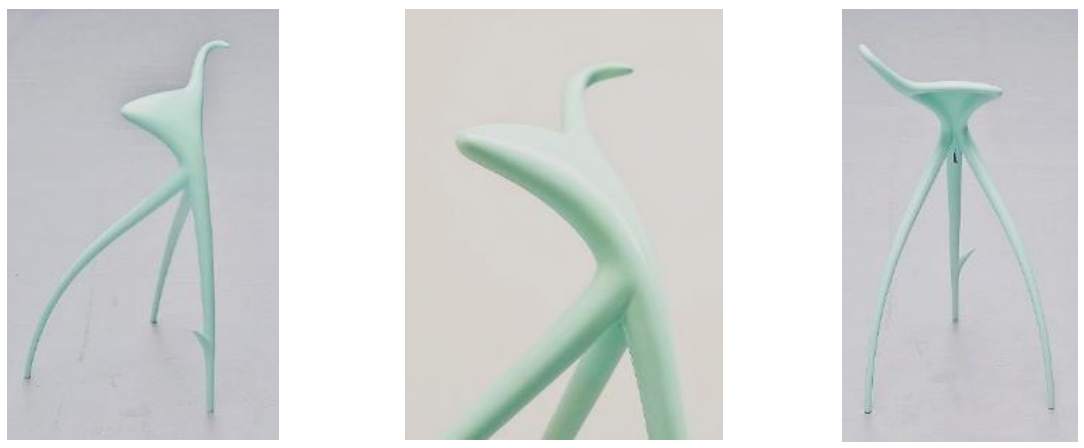

Fonte: Design (2017).

O designer, ao se libertar das estruturas que padronizam e concebem uma cadeira, possui a mente livre para sentir a experiência do sentar, que podemos assim definir como o contato do corpo com qualquer material que se destine ao repouso dos membros inferiores e que nos traz a sensação de prazer quando ficamos muito expostos à posição em pé. Essa experiência de prazer seria o elemento que conduz o designer a relacioná-la com a forma e, consequentemente, com o contato corporal, que deve ser moldado para atingir seu objetivo. 
Essa inovação começa a ocorrer com a descoberta de materiais para a criação da cadeira, desenvolvendo-se, assim, novas formas que, cada vez mais, são análogas às formas humanas.

\section{Materialização da Personalidade.}

"A geleia amorfa dos fenômenos (o "mundo material") é uma ilusão e as formas que se encontram encobertas além dessa ilusão (o "mundo formal") são a realidade, que pode ser descoberta com o auxílio da teoria". (FLUSSER, 2007, p. 23).

Neste estudo, caracterizamos esse fenômeno como personalidade, como a "geleia amorfa" que constrói um conjunto de qualidades inseridas na forma da cadeira. Ela determina aspectos formais dos materiais, como cores, texturas e elementos, os quais se vinculam a uma teoria de representação dos aspectos subjetivos de uma pessoa ou cultura, como o pensar, o sentir e o agir, presentes em contextos de realidade social e vinculados ao propósito de reproduzir essas ações através do objeto estudado.

Diante de toda complexidade em volta de uma definição sólida da concepção de realidade, pede-se aqui uma licença poética que permita ilustrar umas das facetas dessa controversa definição, através de uma associação entre a forma da cadeira e as experiências do usuário - um dos fatores mais importantes para o significado do objeto. Isto é, para cada indivíduo, é possível que exista um significado particular do que seria esse conceito de realidade, uma vez que ele pode ser expresso pela relação entre a forma da cadeira e o modo como cada um se reconhece nela. A acepção da cadeira é expansiva, pois "o potencial de significação dos artefatos vai muito além do princípio, relativamente simples, de agregar valor [...] por meio da visualidade, o design é capaz de sugerir atitudes, estimular comportamentos e equacionar problemas. " (CARDOSO, 2016, p. 115-117). O mesmo autor ainda complementa que o olhar é também sujeito a transformações no tempo, pois existe uma construção social e cultural que acaba determinando seu contexto histórico em cada período.

Como exemplo de materialização de personalidade, no qual uma cadeira caracteriza a individualidade de uma pessoa, apresentamos as cadeiras pintadas por Van Gogh (Figura 2 e Figura 3), que tomam a cena do quadro como objeto único e revelador.

Figura 2 - Cadeira de Vicente e seu cachimbo

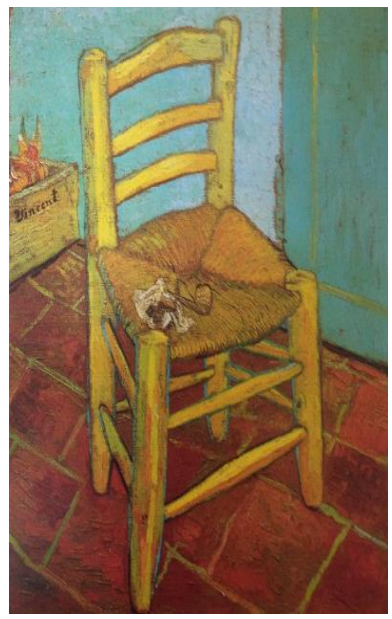

Fonte: Walther; Metzger (1998, p. 10).
Figura 3 - Cadeira de braços de Paul Gauguin

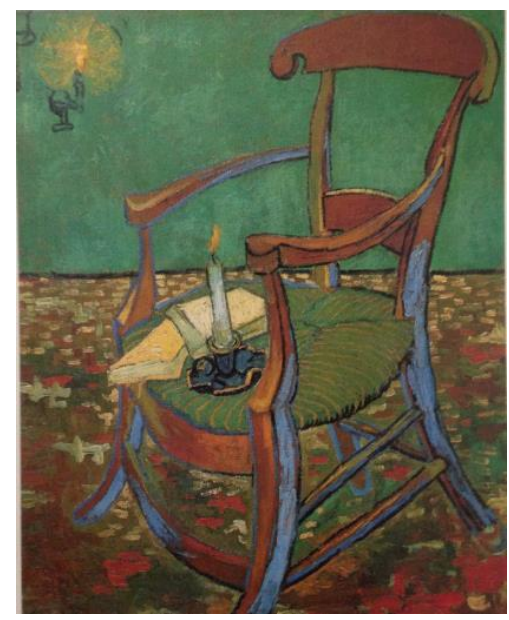

Fonte: Walther; Metzger (1998, p. 10). 
"Justapostas, as cadeiras olhariam uma para outra como se oferecessem um convite à conversa, ao desabafo; ou então, de costas viradas, ter-se-iam afastado uma da outra, como se não tivessem mais nada a dizer e existissem em mundos diferentes". (WALTHER; METZGER, 1998, p. 7).

Walther e Metzger (1998) dizem que essas cadeiras faziam parte da casa de Van Gogh, situada na província de Arles, no norte da França, e eram usadas nos encontros para discussões sobre arte com seu amigo Paul Gauguin, sendo um marcador da amizade presente entre os artistas.

O autor ainda ressalta que a cadeira de Van Gogh (Figura 14) traz um aspecto simples, composta por madeira e palha, aparentando não ser muito confortável, o que os historiadores associam à impressão que Van Gogh tinha de sua vida. De maneira análoga, o artista reproduz essa metáfora na cadeira de braço (Figura 3), que representa as características de elegância e conforto que ele enxergava em Gauguin.

Embora a ausência de um corpo na cadeira não pareça representar, de fato, uma persona, o Calvinismo holandês e a proibição da presença de imagens da Sagrada Família nas obras de arte trouxe uma reflexão sobre como um objeto poderia carregar significados e representar não só ele como toda uma ideologia. O Calvinismo foi um movimento protestante conduzido por João Calvino, no século XVI, um estudioso e filósofo francês que se converte ao Protestantismo, difunde a sua crença teológica tendo como alicerce a Reforma Protestante então iniciada por Martinho Lutero. Ao chegar na Holanda, esse novo movimento tem uma nova roupagem e é chamado de Reforma Teológica ou Fé Reformada e ainda de Calvinismo Holandês. Dentre suas influências na arte, temos como características o desapego ao esteticismo, respeito à consciência e à beleza e rejeição total à ostentação. A cadeira vazia passou a simbolizar, nesse período, as figuras do cristianismo, a exemplo do próprio Cristo, para simbolizar julgamento e poder (WALTHER; METZGER, 1998, p. 8). Assim, Van Gogh se inspirou nessa filosofia e desenvolveu uma perspectiva própria, carregando, nas cadeiras, significados que descrevem seu cotidiano e aspectos emocionais. "Gauguin está lá, sentado na sua cadeira de braços, mesmo que não possamos ver." (WALTHER; METZGER, 1998, p. 8).

A ostentação da presença de um corpo em uma cadeira se faz intensa, pois associamos cada parte ao formato humano: as pernas se fazem "pernas" da cadeira, os braços se fazem "braços" de apoio, o quadril se faz assento e as costas o espaldar. Humaniza-se o móvel e ele acaba constituindo um organismo "vivo", que possui personalidade e características concernentes ao corpo.

Por trás das cadeiras vazias de Van Gogh estão sentimentos de melancolia, pensamentos de onipresença da morte; o cachimbo e a bolsa de tabaco representam uma partida, como a imagem que se fixou em sua mente após a partida de seu pai, constituindo assim uma metáfora da crise de todo o século, entre mortes e suicídios.

Com essas reflexões, surgiu um questionamento. Será que a naturalização que damos ao objeto ocorre devido ao acúmulo de memórias e experiências anteriores, como fez Van Gogh, ao atribuir à cadeira referências que a transformaram em um meio de comunicação de seus sentimentos e perdas?

Na tentativa de buscar possíveis respostas, trazemos a autora Damázio (2013), que relaciona a memória com os objetos:

"A memória, portanto, engloba passado, presente e futuro e, também, lembrança e esquecimento [...] Em resumo, vivemos, lembramos e esquecemos em sociedade e em um mundo físico. E as coisas são a parte tangível de nossa identidade e memórias". (DAMÁZIO, 2013, p. 46) 
Essa identidade e essa memória nos remetem ao cotidiano, cujo fluxo de informações e atividades rotineiras acaba gerando interpretações acerca dos objetos. Utiliza-se essa observação da realidade para gerar formas e, portanto, "imaginar as situações, atividades e relações humanas desejadas em torno do que foi imaginado" (DAMÁZIO, 2013, p. 57). Trata-se de um contexto que resulta em objetos cada vez mais semelhantes a algo familiar. A cadeira, aqui, é a própria expressão do corpo que, por sua vez, é o fato gerador de sua forma. Se "as coisas são a parte tangível de nossa identidade e memórias", então podemos pensar que a cadeira é o retrato do corpo humano que identifica e reflete a memória de sua forma.

Assim como a cadeira, os artefatos são construídos por meio da cultura e das trocas simbólicas entre o próprio criador e a sociedade. Um exemplo notável dessa permuta foi a criação do ícone da Cadeira Mole, em 1957, pelo designer Sérgio Rodrigues (Figura 4) que, segundo Cardoso (2016), pela sua forma, sugeria atitudes. Quando foi encomendada pelo fotógrafo Otto Stupakoff, ele solicitou um sofá esparramado, carregando, assim, um suposto jeito brasileiro de sentar, até sendo considerada precursora da Bossa Nova e símbolo da modernidade nacional (CARDOSO, 2016, p. 118). Em 1961, a cadeira de Rodrigues ganhou o "IV Concurso Internacional do Móvel", sendo identificada pelo seu clima de casualidade, produzido pelas almofadas, transmitindo uma acentuada brasilidade, por utilizar, em sua estrutura, madeira e correias de couro que moldam o corpo ao sentar.

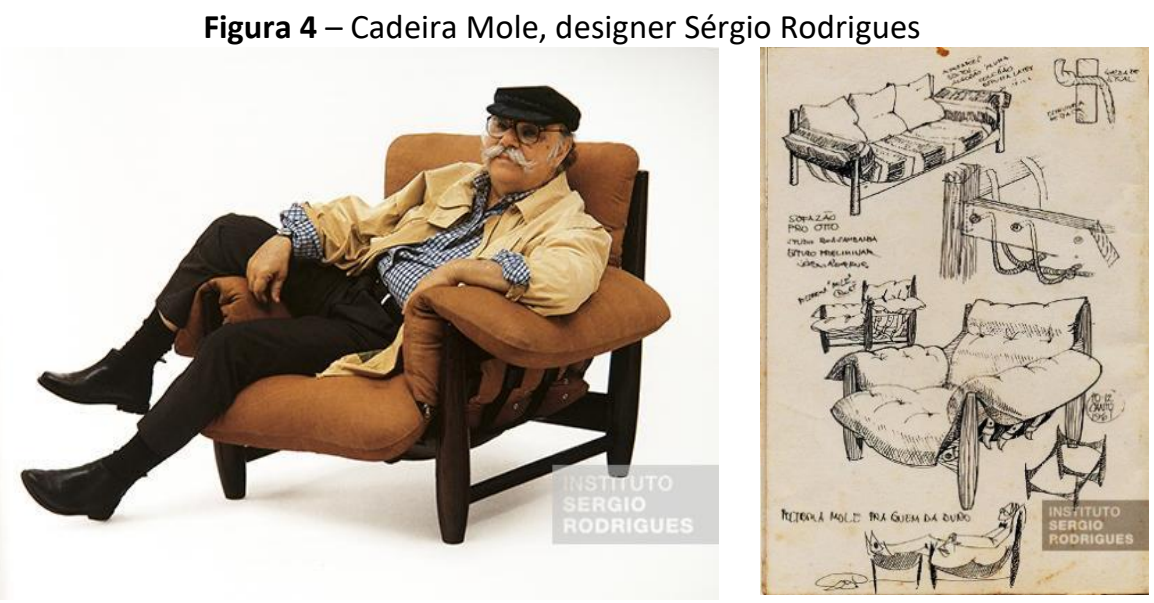

Fonte: Zappa (2017)

A moldagem já é uma característica artística que vem das esculturas, moldadas à mão, o que a individualiza como meio de liberdade de expressão do artista, que deixa ali suas digitais e seu traço, que é único e revelador, carregando uma densidade poética para a obra. Quando o objeto passa também a unir essas particularidades, ele se transforma e traz uma hibridização entre arte e design.

Um exemplo notório dessa união aconteceu em 1955, com a cadeira Ant (Figura 5), que, em português, significa formiga, do designer Arne Jacobsen, modelo 3107, feita com madeira compensada moldada, sendo que o autor primeiramente a modelou em argila para encontrar as curvas corretas e, depois, construiu o seu protótipo. 
Figura 5 - Cadeira Arne (Modelo 3107)

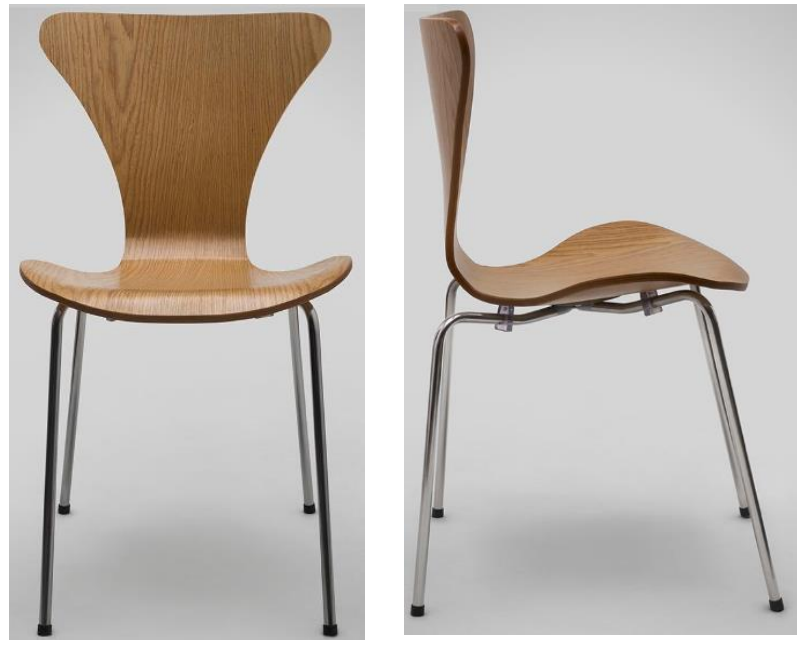

Fonte: Artesian (2017)

A moldagem acaba sendo um recurso utilizado pelo designer para sentir a curva orgânica do corpo e ele aplica essa técnica para várias outras criações, como a poltrona Egg (Figura 6), que "une a pureza da forma com a acessibilidade e o calor orgânicos. A impressão é de que ela convida você a se sentar" (DESIGN MUSEUM, 2011, p. 47). Considerada um contraste escultural, quando comparada às linhas retas e racionais de uma arquitetura, suas formas também foram estudadas com a moldagem pela argila, procedimento no qual o designer se empenhou para encontrar a forma perfeita da concha que aplicou pela primeira vez em 1958 com uma espuma firme sob o estofamento, criando uma espécie de espaço privativo para quem se senta.

Figura 6 - Poltrona Egg (1958)

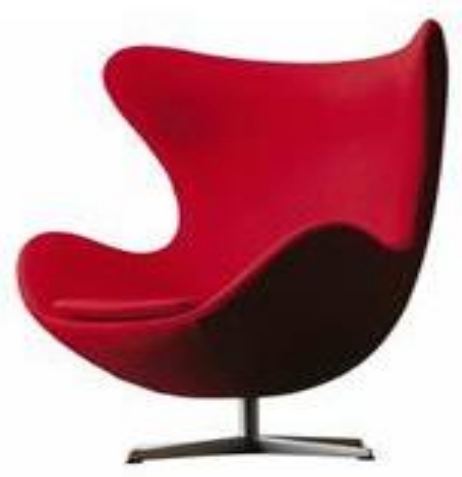

Fonte: Design (2017)

Com os exemplos citados, conseguimos perceber que as formas das cadeiras, constituem recipientes construídos especialmente para os fenômenos ${ }^{1}$, como reforça Flusser (2007), indicando a personalidade que caracteriza e determina a forma da cadeira como materialização desse

\footnotetext{
${ }^{1}$ Fenômeno - "A geleia amorfa dos fenômenos (o "mundo material") " (FLUSSER, 2007), que se materializa na cadeira através da forma do corpo.
} 
fenômeno.

Chegamos à conclusão de que a personalidade é a característica fundamental para essas cadeiras, pois elas acabam transcendendo sua função originária do sentar para trazer significados que atraem, de outra forma, o usuário.

\section{Aspectos da Forma: A Experiência do Usuário com o Objeto}

Segundo Cardoso (2016), a forma possui três aspectos que se interligam. A aparência é o aspecto perceptível ao primeiro olhar. Esse primeiro aspecto se caracteriza como primeira impressão causada ao consumidor, que, de imediato, podemos supor ser guiada pela forma, juntamente com a cor predominante. A configuração constitui o sentido composicional, a ideia da forma da cadeira, trazendo a identificação do artefato como tal e, normalmente, caracteriza sua função. O terceiro aspecto, a estrutura, refere-se à dimensão construtiva ou constitutiva, ou seja, à sensação ou experiência que o consumidor traz referente ao seu contato com o artefato.

Entrando no âmbito do design emocional, Norman (2008) o categoriza em três estágios: design visceral; design comportamental e o design reflexivo. Norman (2008) relaciona esses níveis a estruturas do cérebro. O visceral é o que faz julgamentos rápidos; no comportamental, as ações são controladas pelo corpo; e o reflexivo está diretamente ligado ao poder de interpretação. Assim, a emoção se faz presente para a concepção do design, tendo a cadeira como um objeto que pode modificar o conforto e indiciar a forma do corpo adequada para que seu objetivo seja alcançado, identificando a presença do design visceral, que privilegia a aparência, ou a racionalização do objeto em detrimento da funcionalidade e alcançando o nível reflexivo quando se "espelha" ao corpo, caracterizando o objeto como referência artística.

Observando os dois autores, conseguimos relacionar a tríade entrelaçada em cada conceito, encontrando a seguinte comparação:

Quadro 1 - Comparação entre as teorias dos autores

\begin{tabular}{ll} 
Rafael Cardoso (2016) & \multicolumn{1}{c}{ Donald Norman (2008) } \\
\hline Aparência & Design Visceral \\
Configuração & Design comportamental \\
Estrutura & Design reflexivo
\end{tabular}

Fonte: Elaborado pela autora.

Todos os três aspectos encontrados pelos autores formam um conjunto indissociável, caracterizado pela inviabilidade de se estudar cada um de maneira isolada, devido, sobretudo, à subjetividade dos conceitos e à pessoalidade que eles carregam simultaneamente, explicitando, assim, significados que podem ser transformados por cada indivíduo e criando funções distintas da origem do artefato, como vemos na Figura 7, em que a cadeira passa a ser suporte de apoio, como uma prateleira, e sua estrutura é fixa na parede, servindo também de cabideiro para camisas. 
Figura 7 - Funções distintas da origem da função da cadeira

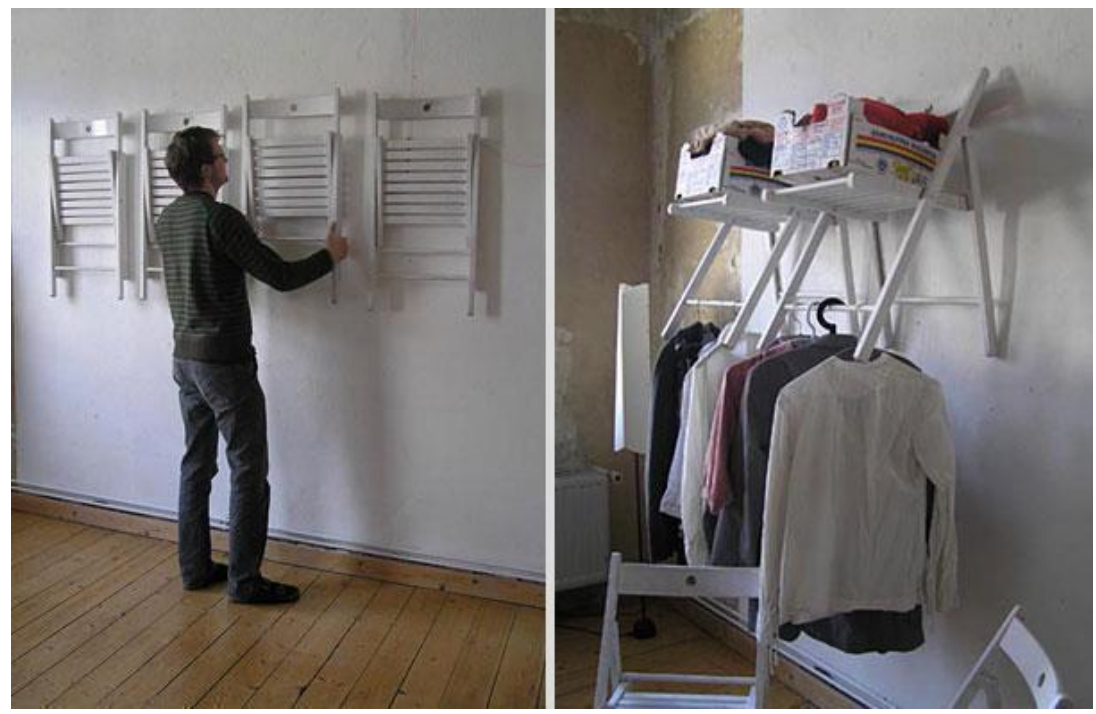

Fonte: Science (2017)

Para que haja função é preciso haver consenso social quanto ao objetivo para o qual o objeto é usado, ou seja, é preciso que a sociedade saiba identificar a função de cada produto [...]. Também pode ocorrer de um objeto ganhar outra função que não foi aquela para a qual ele foi produzido ou, com o tempo, de um objeto perder sua função convencional e ganhar outra. (CORRÊA; SILVA, 2013, p.13)

Pontuamos então, que os objetos compõem a vida do ser humano para manter uma necessidade inerente à função para a qual foram destinados num presente emergente.

Entretanto, a significação da cadeira se coloca de forma contraditória. A história do artefato é intrínseca a uma sociedade industrializada, que a compreende como uma ótica utilitarista, que segue um padrão. Mas novas necessidades são criadas a todo o momento, e "as formas falam, sim" e criam uma nova relação com o indivíduo: "basta apenas saber ouvir suas vozes" (CARDOSO, 2016, p. 131-132). Com isso, percebemos a dependência do coletivo para encontrar a função da cadeira, no qual seu uso é manipulável.

Faz-se, então, necessária a criação de uma linguagem das formas, constituída pela expressividade das formas ou pela semântica do produto, uma vez que a possibilidade de expressão para os materiais que nos cercam é limitada. Porém a densidade poética atribuída exclusivamente a obras de arte deve também ser compartilhada pela produção do design, desassociando-se da concepção de uma mera máquina de cópias que produz objetos facilmente descartáveis e transformando-se numa máquina capaz de produzir características físicas que determinem e transmitam um sentido abstrato. Redefine-se, assim, o vínculo entre o objeto e seu consumidor, uma vez que a aquisição do objeto, assim, se dá pelo sentido que ele carrega. Tem-se, então, que o artefato está constituído, agora, por discursos verbais, imagéticos e híbridos, que unem a matéria com a densidade poética.

Quando "o produto deixa de ser uma finalidade e torna-se somente um fator no movimento da cadeia de consumo" (JÚNIOR, 2009, p. 27), não possuindo uma densidade poética, acaba sendo replicado pela indústria e se destina, com o tempo, ao lixo (Quadro 02). O objeto é substituído por uma imagem frágil e de fácil desgaste, tornando-se obsoleto e massificado, importando somente a 
novidade do momento, pois, "afinal, lixo nada mais é do que a matéria desprovida de sentido ou propósito." (CARDOSO, 2016, p.133).

\begin{tabular}{ccc}
\hline & Quadro 02 - Ciclo dos objetos descartáveis \\
\hline $\begin{array}{c}\text { Projeto que não atribui } \\
\text { densidade poética }\end{array}$ & $\begin{array}{c}\text { Sociedade industrial }= \\
\text { repetição }\end{array}$ & Resulta em lixo \\
\hline &
\end{tabular}

Fonte: Elaborado pela autora.

Quando acontece a inversão desse ciclo, e o objeto possibilita uma expressão significativa, como uma obra de arte, dificilmente seu destino será o lixo (Quadro 03). "O modelo ideal era a obra de arte, objeto que perdurava sem perder seu valor" (JÚNIOR, 2009, p. 27)

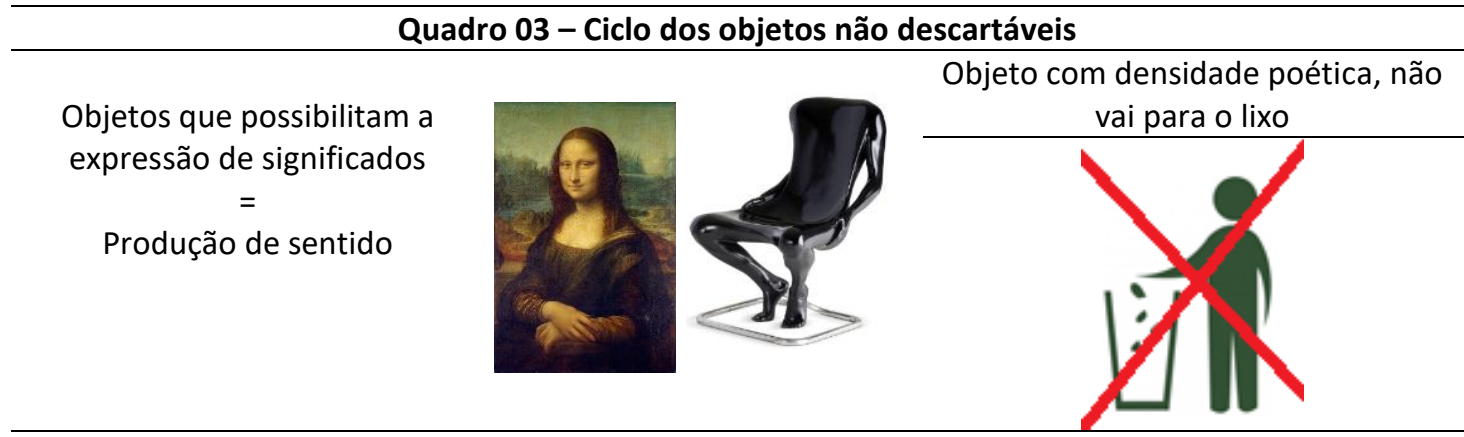

Fonte: Elaborado pela autora.

Podemos perceber através dos Quadros 02 e 03, que há razões para considerar a utilização da linguagem das formas na criação objeto, para que ele possua uma densidade poética, acarretando ao artefato sentidos que levem o consumidor a pensar a continuar com o objeto, sem descartá-lo.

Cardoso (2016) ainda complementa que, na sociedade industrial, existe a tendência de construir o sentido do artefato a partir do encontro de três fatores - fabricação (autoria e origem); distribuição (mercado e comércio) e consumo (compra e uso) -, encontrando-se, nesses fatores, o caminho que, muitas vezes, não contribui para a construção da linguagem formal dos artefatos, pois ocorrem bloqueios que gerariam significados. Entretanto,

"[...] o que importa em termos de design, é que a capacidade das formas de comunicar informações à mente humana é muito mais profunda e abrangente do que "simplesmente" 
o conjunto de significados impostos pela sequência fabricação, distribuição e consumo". (CARDOSO, 2016, p. 141)

Observando o visual da cadeira Thonet, modelo 209 (Quadro 04), através dos aspectos dos materiais e da forma, conseguimos analisar profundamente sua significação. Segundo os estudos de Teixeira, Matos e Parassi (2011), esse é um campo de interação dos valores visuais da forma, cujo objetivo é demonstrar que a forma da cadeira, além de indicar sua função prática, é também símbolo de elegância, leveza e formalidade (ou solenidade).

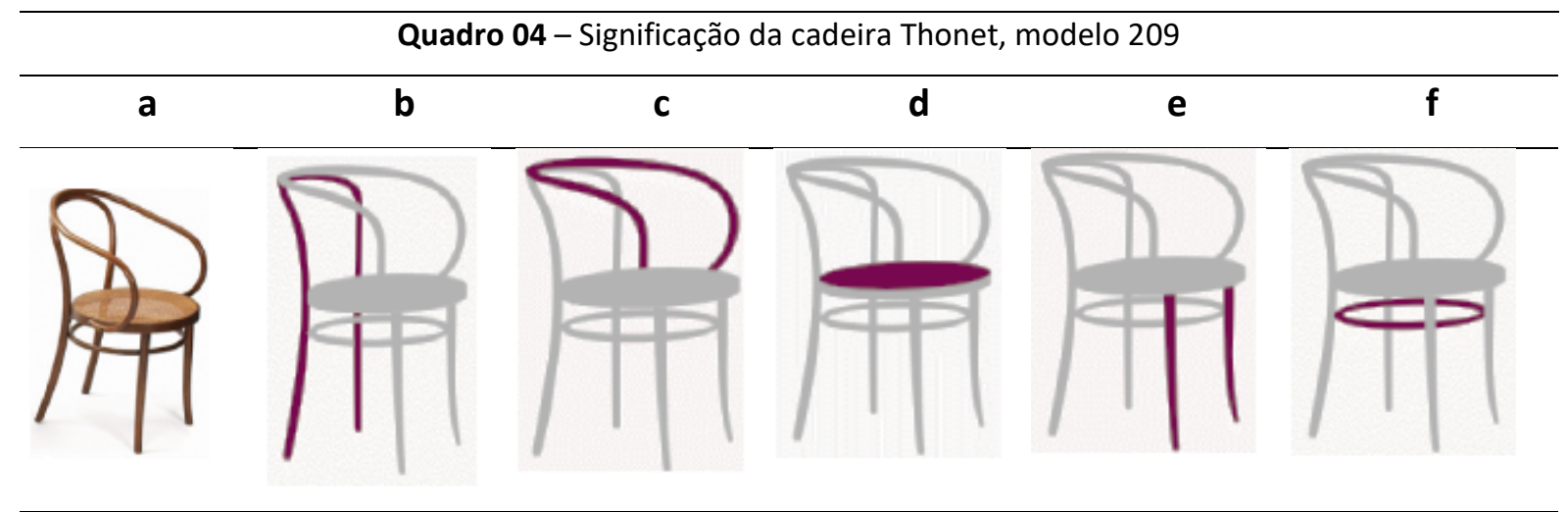

Fonte: Teixeira; Matos; Parassi (2011), adaptado pela autora.

A primeira análise é feita através dos materiais (Quadro 04-a): a cadeira é composta por madeira e palha, sendo utilizada madeira sólida e vergada. Observando a imagem da cadeira em geral, notamos que ela apresenta sinuosidade em toda sua estrutura. As linhas do encosto são curvas (Quadro 04-b), e a linha que compõe os braços desenha três curvas, uma horizontal e duas verticais (Quadro 04-c). Além disso, o plano que expressa o assento da cadeira é circular (Quadro 04-d), além de outra estrutura circular que tangencia e fixa por dentro as quatro pernas (Quadro 04-f), sendo que as pernas posteriores (quadro 04-e) são elementos verticais simétricos com as outras duas pernas e ainda carregam certa curva. Chega-se a um conjunto de curvas dominante em toda a composição, que se mostra predominantemente orgânica.

O sentido orgânico é reforçado no uso dos materiais: madeira e palha, que são materiais orgânicos e que foram utilizados na construção da cadeira representada pela imagem. Os movimentos curvos e circulares dos elementos e a estrutura vazada da cadeira relacionam a imagem da peça com as sensações de dinamismo e de leveza. Um objeto que mostra uma estrutura sinuosa e vazada será percebido como leve e dinâmico, mesmo que esteja imóvel e apoiado no solo sobre quatro pés. A leveza e o dinamismo associados ao conceito de orgânico poderiam também propor temas ou significações de liberdade e desordem. (TEIXEIRA; MATOS; PARASSI, 2011, p.105)

A subjetividade entra aqui como adjuvante de um papel importante para o cenário do design emocional, o qual é resultante do casamento entre a psicologia e o design, trazendo duas perspectivas sobre a experiência, que são adotadas na área: Userexperience (ou experiência de usuários) - humano e computador - e o Productexperience (ou experiência com produtos) humano e produto (RUSSO; HEKKERT, 2008, p.32). Essa última é a proposta na qual se vincula um conjunto de efeitos provocados pela interação entre uma pessoa e um produto, gratificando a experiência estética, a experiência de significado (os significados apegados aos produtos) e a experiência emocional (os sentimentos e emoções que são evocados). 
Essa proposta de design carrega consigo o sentimento e a emoção oriundos de uma experiência do usuário com o produto, importando, assim, sua vivência e os significados adquiridos ao longo do uso do produto. "Definimos o amor como uma forte afeição por produtos, derivada de relacionamentos e laços pessoais entre um indivíduo e um produto. " (RUSSO; HEKKERT, 2008, p. 36).

A mesma autora aborda os princípios desse sentimento como um meio de permear a experiência, o que envolve processos como interpretação, recuperação de memória e associação, o que chama de interação fluída; nomeia o produto com valor simbólico como lembrança de memória afetiva, afirmando que os "produtos que contêm memória afetiva são insubstituíveis, manipulados com mais cuidado, limpos com mais frequência, e até seu uso é evitado". Mugge et al. (2005, apud Russo; Hekkert, 2008) "propõem que designers podem influenciar o apego entre pessoas e produtos ao incentivarem a associação de memórias". O significado simbólico (social) também faz parte de um repertório no qual os "produtos encorajam e facilitam a construção e familiarização da auto identidade de uma pessoa [...] podem satisfazer prazeres sociais". Ainda ocorre também o compartilhamento de valores morais, no qual o consumidor adquire, através do produto, a experiência de prazeres sociais, transferindo um senso de responsabilidade. $E$, por último, a interação física_prazerosa, que consiste em dar prazer ao usuário através do contato físico com o produto, "mas também nos torna conscientes quanto ao nosso próprio corpo, o que forma a base da experiência do próprio ser." (Hekkert, 2006, p. 43).

Segundo Buzetto (2007), “A cadeira não é um objeto simplesmente, mas sim a memória e as lembranças de quem já passou por ela, as recordações das alegrias, das frustrações e as tristezas pensadas. " (NAVES, 2007 apud BUZETTO, 2014, p. 71). Diante desse contexto, podemos dar como exemplo a cadeira balanço Thonet (Figura 8), que resgata a memória afetiva de quem a possui e que Buzetto (2007) caracteriza a partir de três fatores: afeto, memória e desejo.

Figura 8 - Cadeira balanço - Catálogo de Thonet (1895)

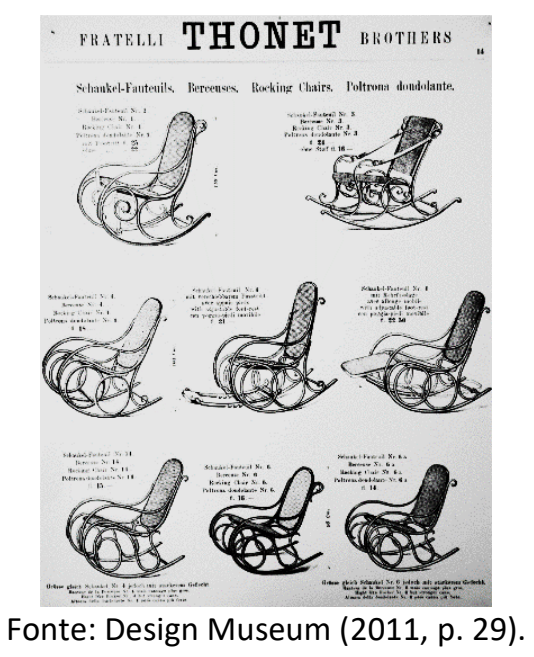

O mesmo autor ainda complementa dizendo que ela faz parte de um campo fenomênico da percepção humana, causando uma atmosfera de sentimentos: "o objetivo da retórica não consiste só em convencer, mas também, e, sobretudo, em seduzir" (BONSIEPE, 2011 apud BUZETTO, 2014, p.72), criando uma atmosfera do belo sedutor, ressignificada para o usuário. $E$, sendo o objeto 
analisado pelo sentido, o usuário reconhece a forma pela necessidade e, em seguida, pela emoção,

[...] uma possibilidade inerente aos objetos da percepção, por serem emocionalmente contaminados pela nossa percepção e necessidade de afeição. E, considerando que somos seres sociais, há nesta matriz sensível de ressignificação um forte elemento de mediação com os costumes e a cultura, no momento que esses objetos são produzidos e/ou percebidos pelos sujeitos. (BUZETTO, 2007, p.73)

Outro princípio em que, na verdade, só se muda a terminologia, é o design atitudinal, proposto por Lucy Niemeyer.

O design atitudinal resulta do estudo de interações do ser humano com o produto, para estudar os relacionamentos entre os aspectos físicos dos produtos e suas influências afetivas. Ele objetiva também aplicar o conhecimento construído com vistas a projetos que satisfaçam mais o aspecto subjetivo do destinatário e sejam significativos para ele. $O$ foco do design atitudinal, então, é a interação da eficiência com a significação, com as qualidades mais hedonistas dos produtos, em que as experiências positivas e prazerosas são fins em si mesmas. (NIEMEYER, 2008, p. 55)

Trata-se de um conceito que concebe o produto como algo agradável, interferindo diretamente nos produtos impessoais e estritamente funcionais, acrescentando-lhes outros fatores além da usabilidade, como valores culturais e sociais, a observação das condições de ocorrência de sua utilização e suas qualidades simbólicas, evitando os produtos tradicionais, projetados só com vistas a seu apelo estético, a sua usabilidade e (ou) funções e possibilidades tecnológicas. Investese, pois, na possibilidade de produtos que tragam para o consumidor uma relação com o nível subjetivo, emocional e cognitivo, ou seja, promovam novas experiências entre o usuário e o produto.

Segundo Cardoso (2016), existem quatro fatores que determinam a significação dos artefatos:

- materialidade: construção, estrutura, forma e configuração do objeto;

- ambiente: o entorno, a situação, a inserção social, o contexto de uso, pois cada vez que o artefato muda de contexto, muda seu sentido;

- usuários do artefato: seu repertório, gostos, comportamento, requisitos ergonômicos, ideias ou intenções;

- tempo: o impacto da sua passagem do tempo sobre o objeto em questão.

Resumidamente, Cardoso (2016), traz a configuração apresentada no Quadro 5 para explicitar o significado do artefato, analisando diversos aspectos.

Quadro 05 - Significação do artefato

\begin{tabular}{|c|c|c|}
\hline $\begin{array}{c}\text { ASPECTOS DA FORMA QUE SE } \\
\text { INTERLIGAM }\end{array}$ & $\begin{array}{c}\text { SENTIDO DO ARTEFATO PARA A } \\
\text { SOCIEDADE INDUSTRIAL }\end{array}$ & $\begin{array}{c}\text { FATORES DA SIGNIFICAÇÃO DA } \\
\text { FORMA }\end{array}$ \\
\hline Aparência & Fabricação & Materialidade \\
Configuração & Distribuição & Usuários do artefato \\
Estrutura & Consumo & \\
\hline
\end{tabular}

Fonte: Elaborado pela autora. 


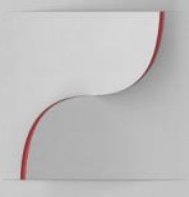

Pesquisa \&

Desenvolvimento

em Design

\section{Artigo Completo}

O quadro mostra os atributos que cada elemento possui. Eles interagem entre si e se interligam por aspectos relevantes ao objeto, no qual a aparência atinge a primeira impressão que, por sua vez, se relaciona com a fabricação, que é a origem do artefato, o qual, por fim, se constitui através da materialidade.

A configuração expressa o sentido composicional que encontramos na sua forma, que influencia na distribuição para o comércio e no ambiente, através do contexto de uso e da inserção social.

A estrutura traz a experiência com o consumo, que está intimamente relacionado aos gostos e comportamentos dos usuários do artefato.

Mas todos esses elementos citados, independentemente de hierarquias ou conceitos, convivem com o tempo. Para conseguir compreender os artefatos, faz-se necessário ter a consciência de que eles podem mudar, a depender do momento e dos fatores que o estabelecem, sendo o tempo o fator que engloba todas as categorias e influencia em seu significado.

\section{Considerações Finais}

Ao estudarmos a cadeira, caracterizamos aqui dois fenômenos: A materialização da personalidade e a experiência do usuário com o objeto. Para esses dois pontos se faz perceber a ostentação da presença de um corpo, seja ele representado pela forma ou por característica de materiais, mas sempre a existência de uma persona.

Encontramos, na cadeira, uma veia artística e de design que a configura como um transporte da forma humana e a simboliza como algo importante para a vivência do cotidiano, além da sua função. Goodman (1984) complementa: "uma cadeira permanece uma cadeira mesmo se nunca é usada como assento [...] dizer o que a arte faz não é dizer o que a arte é." (GOODMAN, 1984, p. 9). A partir dessa reflexão, conseguimos perceber a imensa abordagem que uma cadeira pode propiciar. Carrega símbolos que a intitulam ícone para várias gerações, com valor de cultura material e consequentemente outras relações entre a forma e o significado e muitas vezes subvertendo a ideia preconcebida, que se liberta da estrutura e traz o prazer como elemento que conduz, teoriza e representa aspectos subjetivos, resultando assim em significados particulares dos seus usuários que passam a se reconhecer na forma e a identifica como a própria expressão do corpo, como perfilhamos nas cadeiras pintadas por Van Gogh.

Em paralelo a isso, a experiência do usuário conecta com os conceitos norteados através de aspectos e estágios do objeto, que se interligam, formando sempre uma tríade, um conjunto indissociável, que personifica o objeto gerando significados que se transformam a cada indivíduo, que também dependem do consenso social, mas que buscam unir a matéria com a densidade poética, indo de contra ao que a sociedade industrial tendencia, tendo assim a subjetividade como adjuvante do cenário do design emocional, que trabalha sentimentos como o amor, como meio de permear a experiência, causando uma interação fluida de processos como interpretação, recuperação de memória e associação, uma memória afetiva que se familiariza com o objeto criando uma auto identidade, reconhecendo a forma seguida pela emoção, promovendo consequentemente novas experiências entre o usuário e o produto.

Diante do exposto, compreendemos que o reconhecimento da linguagem estética da cadeira foi imprescindível, para, assim, perceber o potencial comunicativo que ela pode proporcionar a seu 
usuário, constatando ser o tempo um fator que interfere diretamente nas características da cadeira, com o material e seus limites para gerar a forma desejada, determinando hierarquias, funções e classes sociais, vestígios de personalidade e sentidos que conduzem a um conhecimento da alma humana, uma hibridização temporal.

\section{Referências}

ARTESIAN (Org.). Cadeiras Series 7: Arne Jacobsen. 2017. Disponível em: <http://www.artesian.com.br/cadeira-series-7-arne-jacobsen/p>. Acesso em: 29 jun. 2017.

BUZETTO, Denise Maria Chane. A CADEIRA DE MADEIRA TORNEADA: Objeto de desejo doméstico e produção moderna presente na obra "O Importuno”, de Almeida Júnior. 2014. 125 f. Dissertação (Mestrado) - Curso de Mestrado em Artes, Estudos em História, Teoria e Crítica de Arte, Universidade Federal do Espírito Santo, Vitória, 2014. Disponível em: <http://dspace2.ufes.br/jspui/bitstream/10/2112/1/tese_7713_Dissertação FINAL.pdf>. Acesso em: 23 abr. 2017.

CARDOSO, Rafael. Design para um mundo complexo. São Paulo: Ubu Editora, 2016.

CORRÊA, M.; SILVA, C. Os objetos e seus usos. Cultura Visual, Salvador, v. 19, p.11-26, jul. 2013. Edufba.

COSTA JÚNIOR, Hely Geraldo. ENTRE ARTE E DESIGN: Sobre afectos e afecções na obra de Guto Lacaz. 2009. 124 f. Dissertação (Mestrado) - Curso de Arte e Tecnologia da Imagem. Universidade Federal de Minas Gerais / Escola de Belas Artes, Minas Gerais, 2009. Disponível em: <http://www.gutolacaz.com.br/artes/textos/ArteDesign.pdf>. Acesso em: 19 abr. 2017.

DAMAZIO, Vera. Design, memória, emoção: Uma investigação para o projeto de produtos memoráveis. In: 2013. Cadernos de estudos avançados em design: Emoção. Minas Gerais: Eduemg, 2013. p. 43-62.

DESIGN, Mass Modern (Org.). Philippe Starck: WW stool Vitra Germany 1990. Disponível em: <http://massmoderndesign.com/gallery-detail/philippe-starck-ww-stool-vitra-germany-1990>. Acesso em: 31 mar. 2017.

DESIGN MUSEUM (Ed.). Como criar uma cadeira. Belo Horizonte: Editora Gutenberg, 2011.

FLUSSER, Vilém. O mundo codificado: Por uma filosofia do design e da comunicação. São Paulo: Cosac Naify, 2007.

GOODMAN, Nelson. When is art? In: Ways of worldmaking. Indianapolis, Indiana: Hackett Publishing Company, 1984. p. 57-70.

NIEMEYER, Lucy. Design atitudinal: Uma abordagem projetual. In: MONT'ALVÃO, Cláudia; DAMÁZIO, Vera. Design, ergonomia e emoção. Rio de Janeiro: Mauad X, 2008. p. 49-64.

NORMAN, Donald. Design Emocional: Por que adoramos (ou detestamos) os objetos do dia-a-dia. Rio de Janeiro: Editora Rocco Ltda, 2008.

RUSSO, Beatriz; HEKKERT, Paul. Sobre amar um produto: Os princípios fundamentais. In: MONT'ALVÃO, Cláudia; DAMÁZIO, Vera. Design, ergonomia e emoção. Rio de Janeiro: Mauad X, 2008. p. 31-48.

SCIENCE, Hupe (Org.). Cadeira vira estante ou armário. 2017. Disponível em: 
<http://hypescience.com/23-maneiras-criativas-de-reaproveitar-coisas-antigas/>. Acesso em: 29 jun. 2017.

TEIXEIRA, Julio Monteiro; MATOS, Luana Marinho; PERASSI, Richard. Analise semiótica da imagem de uma cadeira. Estudos Semióticos, São Paulo, v. 7, n. 2, p.102-109, maio 2011. Disponível em: <http://www.fflch.usp.br/dl/semiotica/es>. Acesso em: 07 abr. 2017.

WALTHER, Ingo F.; METZGER, Rainer. Van Gogh: Obra Completa de Pintura. Lisboa: Taschen, 1998. ZAPPA, Regina. A Mole: ícone do design nacional. Disponível em: <http://www.institutosergiorodrigues.com.br/Biografia/18/A-Mole-icone-do-design-nacional>. Acesso em: 31 mar. 2017. 